\title{
A unified analysis of two reduplication processes in Saraiki
}

\author{
JEROEN VAN DE WEIJER ${ }^{1 *}$ (1) and FIRDOS ATTA ${ }^{2}$ \\ ${ }^{1}$ Shenzhen University, Shenzhen, China \\ ${ }^{2}$ Lasbela University of Agriculture, Water and Marine Sciences, Uthal, Pakistan
}

Received: May 30, 2020 • Accepted: August 14, 2020

(c) 2020 Akadémiai Kiadó, Budapest

\section{ABSTRACT}

We analyse two reduplication processes in Saraiki, an Indo-Aryan language spoken in Pakistan. The two processes are only minimally different: the first type involves total reduplication and the second type involves overwriting with an initial consonant ("fixed segment reduplication"). The goal of the paper is to expose the difficulties of analysing both processes in a single grammar, i.e. with a single constraint hierarchy in Optimality Theory: we finally opt for an analysis based on allomorphy for the second type, to capture the morpheme-specific nature of the processes involved.

\section{KEYWORDS}

Saraiki, reduplication, fixed segmentism, Optimality Theory, allomorphy

\section{INTRODUCTION}

Reduplication is the systematic repetition of (part of) a phonological base. It is a morphological process which can serve different semantic purposes in different languages, either iconically, e.g. to form a plural, intensive, or distributive, but also other (non-iconic) meanings, such as to express a particular tense or conversion between word classes. Since the base and the reduplicant (RED) are phonologically and morphologically related, an identity relation exists between them which can be captured by way of Optimality Theory (OT) output constraints (Prince \& Smolensky (2004 [1993]), McCarthy and Prince (1995)). These relations can be formally different:

\footnotetext{
*Corresponding author. E-mail: jeroen.van.de.weijer@gmail.com
} 
sometimes the process copies the whole word, as shown in (1a) below, referred to as total reduplication. In other languages, reduplication is partial and the reduplicant consists of only part of the base, as in (1b).

(1) a. Total reduplication in Indonesian (Cohn 1989)

wanita 'woman' wanita-wanita 'women'

buku 'book' buku-buku 'books'

b. Partial reduplication in Banoni (Lincoln 1976, Lynch \& Ross 2002)

resi 'to grate coconut' re-resi 'coconut grater'

sogu 'to husk coconut' so-sogu 'coconut-husking stick'

There are many variants of full and partial reduplication: sometimes the whole word is copied accompanied by a vocalic change, as in Malay gopoh 'haste' $\rightarrow$ gopoh gapah 'hurriedly' and sana 'there' $\rightarrow$ sana sini 'there and here', or it may involve a change of a consonant (often an initial one), as in Tamil kastam 'difficulty, trouble' $\rightarrow$ kastam nastam 'difficulty and loss' (Nadarajan 2006); cf. also English words such as chit-chat and criss-cross. For more examples and analyses of reduplication, see Wilbur (1973), Moravcsik (1978), Marantz (1982); Prince \& Smolensky (2004 [1993]), McCarthy and Prince (1995), Kager (1999), Urbanczyk (1999), Hurch (2005), Inkelas and Zoll (2005), Urbanczyk (2007), Frampton (2009), among many others.

Beside repeating a whole word or part of a word, reduplication may also involve a fixed segment. Fixed segment reduplication is a process in which the base is copied but some specific segment(s) must appear phonetically in the output form. An example involves the case of English table $\rightarrow$ schmable, bias $\rightarrow$ schmias (see e.g. Alderete et al. (1999), Nevins \& Vaux (2003)), where the fixed segments are $/ \int \mathrm{m} /$. Other cases involve Yoruba nominalization (Akinlabi 1985), where the (partial) reduplicant must have the fixed vowel /i/ such as in gbona ' be warm, hot' $\rightarrow$ gbi-gbona 'warmth, heat' and dara 'be good' $\rightarrow$ di-dara 'goodness': the CV reduplicant always contains this vowel. In other languages the fixed segment is a consonant, as in Modern Hindi (Singh 1969): pãnĩ 'water' $\rightarrow$ pãñ vãnĩ 'water and the like' and $k^{\mathrm{h}}$ anã 'food' $\rightarrow \mathrm{k}^{\mathrm{h}}$ anã vanã 'food and such kinds of things': the reduplicant always starts with /v/. Since a fixed segment necessarily affects the extent to which base and reduplicant match, and often has a dissimilatory effect, in OT terms the question is how this difference between base and reduplicant is motivated.

This article focuses on two reduplication processes in Saraiki. One of these involves full reduplication, and the other involves fixed segment reduplication. The puzzle that will be central in this paper is how both processes can be captured in one and the same constraint hierarchy. Full reduplication demands complete identity of base and reduplicant, whereas fixed segment reduplication involves an extra morpheme (the fixed segment) that precludes complete identity, so that base-reduplicant identity is not absolute. The challenge is to find general constraints and the correct hierarchy that allows both reduplication processes to be expressed in the same grammar. It is important to emphasize that both processes belong to the same speech style and that they do not involve lexical exceptions, which may be analysed using co-phonologies (e.g. Inkelas \& Zoll (2007)) or lexically indexed constraints (Pater 2000, 2009). In general, using different constraint hierarchies for different parts of the grammar weakens the Optimality Theory approach: one constraint hierarchy should, as much as possible, be used for one language (at least in the same speech style). 
To give one example of an analysis that is 'parochial', i.e. only works for the reduplication process at hand, but is not suitable for the entire language, consider the constraint hierarchy that Soohani (2017: 130) gives for a fixed-segment reduplication process in Balochi (also spoken in Pakistan and in adjacent areas in Iran): ${ }^{1}$

$$
\text { OCP }>\text { FAITH-AFFIX }>\text { MAX-IO }>>{ }^{\star} \text { Ons } / \mathrm{N}>>\text { MAX-BR }>\text { VOP, IDENT-BR (lab) }
$$

Here the constraint ${ }^{\star} \mathrm{ONS} / \mathrm{N}$ is defined as "Word-initial syllables may not begin with nasal" Soohani (2017: 129) and this forces a base that starts with a nasal $/ \mathrm{m} /$ to change this (to a [p]) in its reduplicant (e.g. [mu:d-pu:d] 'hair and so forth'). However, the relatively high-rated ${ }^{\star} \mathrm{ONS} / \mathrm{N}$ makes the prediction that reduplicants that are the result of full reduplication, which the language also has, will show the same change i.e. examples like [mədamda:-mədamda:] 'slowly' (*[mədamda:pədamda:]), [me $\left.\int-\mathrm{me} \int\right]$ 'sheep' $\left({ }^{\star}\left[\mathrm{me} \int-\mathrm{pe} \int\right]\right)$, etc. $\left.{ }^{2}\right)$ are also predicted to change the initial consonant in the reduplicant into [p], if we strictly adhere to OT's principle that one language (or language variety) is governed by one and the same constraint hierarchy. In addition, a central idea in OT is that constraints that may be low-ranked in one language may be high-ranked in another, which means that this analysis predicts that languages might be found in which no syllables (or, minimally, no words) may begin with a nasal (namely, if ${ }^{\star} \mathrm{ONS} / \mathrm{N}$ is top-ranked). This prediction seems likely to be incorrect. Hence, the question is if it is possible at all to analyse both reduplication processes using the same constraint hierarchy, in Balochi or in other languages, or if we need to give up this very basic tenet of Optimality Theory. This article explores exactly this question for Saraiki.

This article is organized as follows: the next section gives a brief introduction to the Saraiki language and presents the data for both reduplication processes in Saraiki (full reduplication and fixed segment reduplication) and attempts to give a unified analysis. Section 3 presents a discussion of the results and concludes.

\section{REDUPLICATION IN SARAIKI}

Saraiki is an Indo-Aryan language spoken in Pakistan. Besides Urdu, it is one of the main languages of Pakistan, spoken in various parts of the country by about 20 million speakers (Gordon 2005). There are six dialects, of which the central variety can be regarded as the (unofficial) standard. The genetic relations between Saraiki and other languages of Pakistan, e.g. Punjabi and Sindhi, are a topic of debate. A preliminary description of Saraiki is available in Shackle (1976) and see, recently, Atta (2019).

Saraiki has both partial and total reduplication. Full reduplication occurs in adjectives, whereas fixed segment reduplication mostly occurs in disyllabic nouns. In section 2.1 we will first give a brief introduction to the phonology of Saraiki. In section 2.2 we will give examples of full reduplication and an OT analysis. Section 2.3 deals with fixed segment reduplication.

\footnotetext{
${ }^{1}$ The constraints in (2) are: OCP "Avoid identity in a particular domain" (e.g. identical tones, segments, syllables or words); Faith-Affix "Realize the segments in an affix faithfully"; Max-IO “Don't delete any segments"; Max-BR "Don't delete any segments in the reduplicant that are present in the base for reduplication"; VOP "Avoid voiced obstruents" and Ident-BR(lab) "Don't change the value for [labial] in a reduplicant, compared to the base for reduplication" (see Soohani (2017: 99)). The constraint * Ons/ $\mathrm{N}$ is discussed immediately below (2).

${ }^{2}$ Data collected from a native Balochi speaker.
} 


\subsection{Saraiki: Basic phonology}

Saraiki has forty-nine consonants, including four implosives, and eighteen vowels, which display a limited length as well as an oral vs. nasal contrast. ${ }^{3}$ The consonant and vowel systems of the language are given in (3) and (4), respectively (breathy voiced sonorants are transcribed as aspirated):

(3) The Saraiki consonant system

voiceless plosive
voiceless aspirated
voiced plosive
voiced aspirated
implosive
voiceless fricative
voiced fricative
voiced nasal
breathy voiced nasal
voiced liquid
breathy voiced liquid
voiced semivowel
breathy voiced semivowel

bilabial dental/alveolar retroflex palatal velar glottal

$\mathrm{p}$
$\mathrm{p}^{\mathrm{h}}$
$\mathrm{b}$
$\mathrm{b}^{\mathrm{h}}$
$\mathrm{b}$
$\mathrm{f}$

$t$
$\mathrm{t}$
$\mathrm{d}$
$\mathrm{d}$
$\mathrm{d}$
$\mathrm{d}$
$\mathrm{s}$
$\mathrm{z}$

$\begin{array}{ccc}\mathrm{t} & \mathrm{c} & \mathrm{k} \\ \mathrm{t}^{\mathrm{h}} & \mathrm{c}^{\mathrm{h}} & \mathrm{k}^{\mathrm{h}} \\ \mathrm{d} & \mathrm{j} & \mathrm{g} \\ \mathrm{d}^{\mathrm{h}} & \mathrm{f}^{\mathrm{h}} & \mathrm{g}^{\mathrm{h}} \\ & f & \mathrm{~g} \\ & \mathrm{f} & \mathrm{x} \\ & & \mathrm{y}\end{array}$

$\mathrm{m} \quad \mathrm{n}$

$\eta \quad \mathrm{n} \quad \mathrm{y}$

$\mathrm{m}^{\mathrm{h}}$

$\mathrm{n}^{\mathrm{h}}$

r 1

$r^{\mathrm{h}} \mathrm{l}^{\mathrm{h}}$

$\eta^{h} \quad j^{h}$

$\mathrm{r}^{\mathrm{h}}$

h

$v^{\mathrm{h}}$

(4) The Saraiki surface vowel system

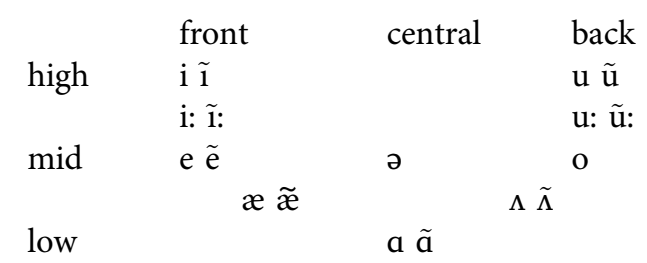

Saraiki also has numerous diphthongs, which are not analysed here. Although the location of stress is to some extent unpredictable, it is mainly trochaic. As for the morphology, verb roots are normally monosyllabic but occasionally also disyllabic, while nouns and adjectives are usually disyllabic (but occasionally also monosyllabic). Examples of some common verbs and nouns are given in (5):

\begin{tabular}{lcll}
\multicolumn{2}{c}{ Verb examples } & \multicolumn{2}{l}{ Noun examples } \\
a & 'come' & fala & 'cobweb' \\
bef & 'sit' & $\mathrm{p}^{\text {h }}$ ala & 'door' \\
kar & 'do' & $\mathrm{d}^{\mathrm{h}} \mathrm{i}$ & 'daughter' \\
gal & 'talk' & asman & 'sky'
\end{tabular}

\footnotetext{
${ }^{3}$ See Atta et al., 2020 for a fuller exposition of Saraiki phonetics.
} 
Saraiki allows some two-consonant onset and coda clusters, but these are mostly restricted to stop + liquid structure in the onset and nasal + stop clusters in the coda. Some examples are given below:

(6)

$\begin{array}{llll}\underset{\Gamma}{\text { druk }} & \text { 'run' } & \underset{r}{\text { trut }} & \text { 'break' } \\ \mathrm{k}^{\mathrm{h}} \tilde{\mathrm{i}} & \text { 'stop' } & \underset{\sim}{\operatorname{draxt}} & \text { 'tree' } \\ \mathrm{k}^{\mathrm{h}} \Lambda \mathrm{nd} & \text { 'sugar' } & \mathrm{p} \Lambda \mathrm{d}^{\mathrm{h}} & \text { 'journey' } \\ \mathrm{amb} & \text { 'mango' } & & \end{array}$

After these preliminaries, we turn to reduplication.

\subsection{Full reduplication in Saraiki}

Full reduplication in Saraiki applies to verbs and adjectives. Consider the examples in (7), of monosyllabic verbs and disyllabic adjectives, respectively:

\begin{tabular}{|c|c|c|c|c|}
\hline \multirow[t]{5}{*}{ a. } & $\mathrm{k}^{\mathrm{h}} \mathrm{a}$ & 'eat' & $\mathrm{k}^{\mathrm{h}} \mathrm{a} \mathrm{k} \mathrm{k}^{\mathrm{h}} \mathrm{a}$ & 'keep eating' \\
\hline & pi & 'drink' & pi pi & 'keep drinking' \\
\hline & $\mathrm{s} \Lambda \mathrm{m}$ & 'sleep' & $\mathrm{s} \Lambda \mathrm{m} \mathrm{s} \Lambda \mathrm{m}$ & 'keep sleeping' \\
\hline & tur & 'walk' & tur tur & 'keep walking' \\
\hline & uddna & 'fly’ & udd్na udda & 'keep flying' \\
\hline \multirow[t]{5}{*}{ b. } & kala & 'black' & kala kala & 'pure black' \\
\hline & $c^{\mathrm{h}}$ ota & 'small' & $c^{\mathrm{h}} \mathrm{ota}_{\mathrm{a}} \mathrm{c}^{\mathrm{h}} \mathrm{otg}_{\mathrm{a}}$ & 'smallest/youngest' \\
\hline & vada & 'big' & vada vada & 'biggest/eldest' \\
\hline & $\operatorname{sun}^{h} \tilde{a}$ & 'beautiful' & $\operatorname{sun}^{h} \tilde{a} \operatorname{sun}^{h} \tilde{a}$ & 'most beautiful' \\
\hline & $\mathrm{ut}^{\mathrm{h}} \mathrm{i}$ & 'furious' & $u_{t}{ }^{h} \mathrm{i}$ ut ${ }^{h_{i}}$ & 'reacting furiously' \\
\hline
\end{tabular}

In verbal reduplication, a continuative imperative meaning is conveyed, and in adjectives a superlative meaning. We will regard these as the same morpheme for the sake of convenience. The underlying form of the morpheme is simply 'RED', a reduplicative morpheme with a specific meaning, but whose segments depend on the base it is attached to.

In Optimality Theory, the analysis of this kind of reduplication is straightforward: base and reduplicant must be exactly identical. In constraint terms, this means that any violation of constraints governing the relation between Base (B) and reduplicant (R) is invariably fatal:

\begin{tabular}{|c|c|c|c|}
\hline kala-RED & MAX-BR & Dep-BR & IDENT-BR \\
\hline a. kala kala & & & \\
\hline b. kala kal & $* !$ & & \\
\hline c. kala kalan & & $* !$ & \\
\hline d. kala gala & & & $* !$ \\
\hline
\end{tabular}


Relevant constraint definitions (McCarthy \& Prince 1995):

MAX-BR No deletion is allowed in a reduplicant (in comparison to the base)

DEP-BR No insertion is allowed in a reduplicant (in comparison to the base)

IDENT-BR No segmental changes are allowed in a reduplicant (in comparison to the base)

For full reduplication, then, the base and reduplicant must be exactly identical. In fact it is impossible to say whether the input form in (8) is $/ \mathrm{kala} /+$ RED or RED $+/ \mathrm{kala} /$, or, in other words, whether reduplication is prefixing or suffixing ${ }^{4}$, since in both cases the result will be exactly the same. In the next section, we will see that it is probably more reasonable to say that reduplication in (8) involves a suffix.

\subsection{Fixed segment reduplication in Saraiki}

Fixed segment reduplication applies to nouns. Consider first the examples in (9), which show that reduplication results in a 'distributive' meaning:

\begin{tabular}{|c|c|c|c|}
\hline $\mathrm{m} \wedge \mathrm{k}_{\mathrm{i}}^{\mathrm{h}}$ & 'fly' & $\mathrm{m} \Lambda \mathrm{k}^{\mathrm{h}} \mathrm{i} \int \Lambda \mathrm{k}^{\mathrm{h}_{\mathrm{i}}}$ & 'flies and such insects' \\
\hline $\mathrm{t}^{\mathrm{h}} \tilde{\mathrm{a}}$ & 'utensils' & $\underline{t}^{\mathrm{h}} \tilde{\mathrm{a}} \int \tilde{\mathrm{a}}$ & 'utensils and things' \\
\hline ot & 'nan bread' & roț $\mathrm{i}$ otti & d, etc.' \\
\hline $\mathrm{k} \wedge \mathrm{p}$ & 'clothes' & kıpre $\int \Lambda p r e$ & nd such things' \\
\hline & 'eye' & $\Lambda \mathrm{k}^{\mathrm{h}} \int \Lambda \mathrm{k}^{\mathrm{h}}$ & other features' \\
\hline$m$ & 'mango' & $a m b \int a m b$ & 'mangoes, etc.' \\
\hline
\end{tabular}

As the data show, the segment [ $\left.\int\right]$ invariably shows up in the reduplicant. The base is unchanged (which suggests that in full reduplication, too, the base is on the left (recall (8)), while the morpheme on the right is the realization of the RED morpheme.

Alderete et al. (1999) present a general OT approach to fixed segment reduplication. In this approach, applied to the case of Saraiki, the fixed segment $/ \int /$ is analysed as part of the input representation. This is a reasonable assumption, because the appearance of this segment is unpredictable and invariable. Faithfulness to the underlying segment is important - crucially, more important than base-reduplicant identity, so it will be realized in the output. An example of an input form, possible candidates and relevant constraints are given in (10), after Alderete et al. (1999: 356):

\begin{tabular}{|c|c|c|c|}
\hline roți-RED- $\int$ & SYLL & Max-10 & IDENT-BR \\
\hline a. roț $\operatorname{rothi}$ & & & * \\
\hline b. $\quad$ roti roți & & $* !$ & \\
\hline c. Joti roti & & $* !$ & $*$ \\
\hline d. $\quad$ Joti Joți & & $* !$ & \\
\hline e. $\operatorname{roti} \int \mathrm{roti}$ & $* !$ & & \\
\hline
\end{tabular}

Constraint definitions:

SYLL $=$ Syllable structure constraints (e.g. no clusters with a fricative, see above $\S 2.1$ ) MAX-IO = Segments in the input should be faithfully realized ("no deletion")

${ }^{4}$ Saraiki allows both prefixes and suffixes for other morphemes. 
In Tableau (10) above, candidate (a) wins, because all input segments are realized, and reduplication has taken place. Base and reduplicant are not identical, so MAX-BR incurs one violation mark. Candidate (b) deserves special attention, because since base and reduplicant are perfectly identical, this candidate represents total reduplication. However, in (b) the input $/ \mathrm{J} /$ is not realized, which is a fatal violation of Max-IO. Candidates (c) and (d) likewise fail, because they have altered the input roots. Candidate (e) is suggested by Nevins's (2005: 280) analysis of a similar process in Urdu-Hindi. For Saraiki, this candidate is not viable, because / $\mathrm{r}$-/ is not a valid onset cluster in the language (recall the data in (6) above), so it will fail as a result of straightforward syllable structure constraints. Other possible candidates, e.g. with $/ \delta /$ after the reduplicant (or infixed), could be ruled out using alignment constraints.

With respect to (10), an important point should be made. Note that the reduplicative morpheme that is involved here is designated as RED, just like the morpheme that was involved in full reduplication in (8) above. This should not obscure the fact that we are dealing with two different morphemes here: they have different meanings, and they attach to different word classes. What they have in common is that they are both reduplicative morphemes and that they are both suffixes (though, as stated above, in the case of full reduplication this cannot be established with certainty). However, this should not obscure the fact that both RED morphemes should be subject to the same constraint hierarchy after attaching to their respective hosts, just like different English morphemes (e.g. plural, ordinal, and past tense) should be subject to the same constraint hierarchy in English. This point will be important below.

A crucial complication arises when the root that is subject to $/ \int /$ reduplication itself starts with $/ \int /$, the specified segment. ${ }^{5}$ Consider the Saraiki examples in (11):

\begin{tabular}{|c|c|c|}
\hline Ji $\int a$ & 'mirror' & Ji $\int a \operatorname{mi} \int a$ \\
\hline $\int a r b \Lambda t$ & 'juice' & $\mathrm{t}$ marb $\Lambda \mathrm{t}$ \\
\hline & 'shawl’ & $\int \mathrm{al}$ \\
\hline fort & 'gravy' & for \\
\hline
\end{tabular}

'mirror and something else'
'juice and other beverages'
'shawls and such things'
'gravy and something'

In all cases, the reduplicant starts with [m], presumably to avoid identity with the base. It is easy to see that the output of $\int \mathrm{i} \int \mathrm{a}-\mathrm{RED}-\int$ (cf. tableau (10), replacing $/ \mathrm{rot} \mathrm{i} / \mathrm{by} / \int \mathrm{i} \int \mathrm{a} /$ ) would be total reduplication ${ }^{*}\left[\int \mathrm{i} \int \mathrm{a} \int \mathrm{i} \int \mathrm{a}\right]$, which is not according to the facts in (11). How could we solve this problem? First, we could propose that the underlying morpheme is $/ \mathrm{m} /$, rather than $/ \mathrm{f} /$ (like in the data in (9)). This would work, as the tableau in (12) shows:

\begin{tabular}{|c|c|c|c|}
\hline Jorva-RED-m & SYLL & Max-I0 & IDENT-BR \\
\hline a. Sorva morva & & & * \\
\hline b. Sorva Jorva & & $* !$ & \\
\hline c. morva Jorva & & $* !$ & $*$ \\
\hline d. morva morva & & $* !$ & \\
\hline e. morva Jmorva & *! & & \\
\hline
\end{tabular}

\footnotetext{
${ }^{5}$ This problem does not arise in the English table-schmable case mentioned above, because schm-onsets in regular English words are non-existent (except for a very few marginal cases like schmuck, schmooze, and schmaltzy, for which there are no spontaneous data involving schm-reduplication; see Nevins and Vaux (2003) for discussion and analysis of elicited schm-reduplication data in such cases).
} 
However, this solution is not optimal, because (as the data in (9) and (11) show), the reduplication process here applies to the same class of words (nouns) and results in the same distributive kind of meaning: this suggests that we are dealing with the same morpheme here, and not two different morphemes. Why should $/ \mathrm{J} /$ be specified in one case, and $/ \mathrm{m} / \mathrm{in}$ the other?

A second possible analysis would be to follow the insight that somehow an alternation is achieved by inserting $/ \delta /$ in reduplicants where the base starts with any consonant other than $/ \int /$, and $/ \mathrm{m} /$ in reduplicants where the base starts with $/ \mathrm{J} /$. Could we use a constraint that demands that base and reduplicant start with different consonants? Such a constraint might be reminiscent of the Obligatory Contour Principle (see (2) above; see also e.g. McCarthy (1986); see Yip (1998) for the relevance of this constraint in reduplication processes) and be formulated as follows:

$$
\begin{array}{ll}
{\left[\mathrm{C}_{1} \ldots\right.} & {\left[\mathrm{C}_{2} \ldots\right.} \\
\text { Base } & \text { Reduplicant } \\
\mathrm{C}_{1} \neq \mathrm{C}_{2} & \left(\text { or: }{ }^{\star} \mathrm{C}_{1} \mathrm{C}_{2} \text { if } \mathrm{C}_{1}=\mathrm{C}_{2}\right)
\end{array}
$$

Such an analysis leaves some questions unanswered, such as which consonant $(/ \mathrm{J} / \mathrm{or} / \mathrm{m} /)$ must be chosen in order to avoid its violation (neither consonant seems especially 'unmarked', so the selection cannot be left to default mechanisms). However this may be, the constraint in (13) would have to be ranked higher than the three Base-Reduplicant identity constraints

\begin{tabular}{|c|c|c|c|}
\hline Sorva-RED- $\int / m$ & Max-I0 & $\mathrm{C} 1 \neq \mathrm{C} 2$ & IDENT-BR \\
\hline a. Sorva morva & & & $*$ \\
\hline b. $\quad$ Jorva Jorva & & $* !$ & \\
\hline c. morva Jorva & $* !$ & & $*$ \\
\hline d. morva morva & $* ! *$ & $*$ & \\
\hline
\end{tabular}
(presented in (8)) to have any effect in the fixed segment reduplication data:

Here the input specifies that either $/ \mathrm{J} /$ or $/ \mathrm{m} /$ can be selected as the output of the morpheme. This means that MAX-IO is not violated for either candidate (a) or (b) in tableau (14), so that the constraint $\mathrm{C} 1 \neq \mathrm{C} 2$ decides the issue in favour of candidate (a). If IDENT-BR were ranked higher than the $\mathrm{C} 1 \neq \mathrm{C} 2$ constraint, the situation would be reversed and candidate (b) would come out as the (wrong) winner. ${ }^{6}$

At this point, however, we should note that the constraint hierarchy in (14) is not suitable for the Saraiki language as a whole, because it would make the wrong prediction for full reduplication, analysed in the previous section. For these data, the wrong prediction is made if the constraint $\mathrm{C} 1 \neq \mathrm{C} 2$ is ranked above the IDENT-BR constraint (and the other BR identity constraints), as tableau (15) shows $(:=$ wrong winner, the form in (a) should be winner):

${ }^{6}$ Or [kala-tala], etc.: the point is that the initial consonants must be different. 


\begin{tabular}{|l|c|c|c|}
\hline kala-RED & Max-I0 & C1 $\neq$ C2 & IDENT-BR \\
\hline a. $\quad$ kala kala & & ${ }^{*} !$ & \\
\hline b. $\odot$ kala fala & & & ${ }^{*}$ \\
\hline c. $\quad$ Jala kala & ${ }^{*} !$ & & ${ }^{*}$ \\
\hline d. $\quad$ Jala Jala & ${ }^{*} !$ & ${ }^{*}$ & \\
\hline
\end{tabular}

This shows that one constraint hierarchy would hold for full reduplication in Saraiki, and another hierarchy for fixed segment reduplication in the same language. This is undesirable, since in Optimality Theory it is assumed that one language has one grammar, i.e. one constraint hierarchy should hold for the entire language. It does not make sense to assume one constraint hierarchy for one rule and another constraint hierarchy for another. Optimality Theory is in this sense a 'responsible' theory: analyses of one phenomenon make predictions for the rest of the language (and, in fact, for other languages by way of the 'factorial typology' (Kager 1999: 34ff): it predicts other languages that would be possible if the constraints that are used in some analysis would be ranked differently). This means that the $\mathrm{C} 1 \neq \mathrm{C} 2$ constraint is not a solution to the problem either: in any constraint ranking in which the latter constraint is ranked above IDENT-BR (as fixed segment reduplication seems to require), the result for full reduplication will yield a wrong winner, because a candidate in which Base and Reduplicant have different initial consonants will always be favoured over a candidate in which they are identical.

It seems that the key to the solution for this conundrum lies in specification. The same morpheme can take different shapes in different circumstances, which is known as allomorphy. Allomorphy in general has been discussed by Lieber (1982), and the OT approach to allomorphy is explored in a number of papers, e.g. Russell (1997), Rubach and Booij (2001), Siptár (2009), and Nevins (2011). Consider a simple example: in English, the indefinite article is either $a$ (as in a house) or an (as in an apple). What is the input form of the indefinite article? It could not be just $a$ because the rule to insert $n$ before a vowel-initial noun is not a regular phonological rule of English (China and ... may get an intrusive $r$ in some dialects, but not $n$ ). Similarly, the underlying form cannot be an, because there is no general rule in English to delete a final $n$ before a consonant-initial word (e.g. maiden wicket), so there would be no way to explain a house. This means that both $a$ and an must be specified in the input form of the article, with specific instructions where each is used:

English indefinite article: $</ ə /, / ə n />$

This allomorphy may be rooted in phonological factors (e.g. the avoidance of onsetless syllables), but these factors are not (or no longer) part of the synchronic grammar, and the allomorphs must be independently listed. In other words, they have been lexicalized as part of the underlying representation of certain morphemes. Either form can appear in candidate realizations and the one that best conforms to the phonological constraint hierarchy of the language is selected, as shown for English in the tableau in (17) (lowered dot = syllable boundary): 
(17)

\begin{tabular}{|ll|c|c|}
\hline \multicolumn{1}{|c|}{ a, an apple } & ONSE & NoCODA \\
\hline a. a apple & $*$ & \\
\hline b. & a.n apple & & \\
\hline & a, an house & ONSE & NoCODA \\
\hline a. a house & & \\
\hline b. an house & & $*$ \\
\hline
\end{tabular}

For the form an apple, the form in (a) will always violate ONSET (or a HIATUS constraint), while an apple never does. This means that the latter will always be selected over the former one (regardless of the position of ONSET in the hierarchy). For the form a house, the candidate in (b) will always violate NoCoDA, while the one in (a) never does. This means that the candidate in (a) will always be preferred over the other, again regardless of the exact position of this constraint in the overall hierarchy.

So, similarly, we can specify both $/ \mathrm{J} /$ and $/ \mathrm{m} /$ in the underlying representation that appears in noun reduplication in Saraiki:

(18) Saraiki noun reduplication: $/ \mathrm{m} /$ after $/ \mathrm{J} / \mathrm{I} / \mathrm{J} /$ after all other consonants; + RED

The difference with the English indefinite article is that the selection cannot be directly determined by the phonological constraint hierarchy. It must be stipulated directly in the input:

\begin{tabular}{|c|c|c|}
\hline 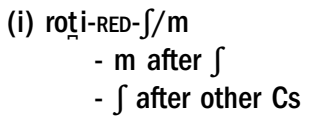 & Max-I0 & IDENT-BR \\
\hline a. roț $\mathrm{fotti}$ & & $*$ \\
\hline b. roți roți & $* !$ & \\
\hline c. roți moți & $* !$ & \\
\hline $\begin{array}{l}\text { (ii) } \int \text { orva-RED- } \int / m \\
-\int \text { other Cs } \\
-m \text { after } \int\end{array}$ & Max-I0 & MAX-BR \\
\hline a. Jorva morva & & $*$ \\
\hline b. $\quad$ Jorva Jorva & $* !$ & \\
\hline
\end{tabular}

The constraint $\mathrm{C} 1 \neq \mathrm{C} 2$ does not need to be stipulated as part of the grammar, which may be an advantage, because it does not hold for other parts of the grammar: for instance, compounds (and any other morphological construction) freely admit two parts that begin with the same consonant: 
(20) Saraiki compounds with identical onset consonants in both parts

$\begin{array}{lll}\text { ber brian } & \text { /b } \Lambda \text { r bria:n/ } & \text { 'desert' } \\ \mathrm{p}^{\mathrm{h}} \text { ika } \mathrm{p}^{\mathrm{h}} \text { ose } & / \mathrm{p}^{\mathrm{h}} \text { ika } \mathrm{p}^{\mathrm{h}} \mathrm{os} / & \text { 'tasteless' } \\ \text { kala kehal } & \text { /kala kifisl/ } & \text { 'pitch-black' }\end{array}$

Probably the same argument can be made for the Balochi forms that were subjected to the constraint hierarchy in (2) above.

Although allomorphy may seem like a rather brute-force solution, we think it can be motivated in this case by the fact that the consonants that are involved in the allomorphy, / $/$ and $/ \mathrm{m} /$, are unpredictable (although the allomorphy is clearly rooted in identity avoidance), and cannot be derived from a common underlying representation. It is therefore reasonable to assume that both are specified, and it has the advantage that the constraint hierarchy that was postulated for full reduplication can be retained for the language as a whole.

\section{CONCLUSION}

The analysis of the two reduplication processes in Saraiki shows that it is important to analyse more than one process in a particular language: a constraint hierarchy that is suitable for one may make the wrong predictions for another. Here we saw that in fixed segment reduplication in Saraiki an analysis involving allomorphy is preferred over some alternatives: it is not possible to analyse both straightforwardly in an OT grammar, because one reduplication process (total reduplication) demands complete identity, and the other one demands a change of initial consonant, even with different choices for roots beginning with different consonants.

One way to interpret this is to realise that morphemes involve more underlying specification than sometimes assumed. In the Saraiki case (and also in the case of English indefinite article) instructions are included when to use which allomorph. This is similar in spirit to the 'Construction Morphology' approach (e.g. Booij (2010)), where the different reduplication processes are different constructions, which may be associated with different phonological rule components. This is not incompatible with the OT approach in which both inputs are subject to the same constraint hierarchy, which therefore still holds for the whole language. We hope that similar analyses of multiple reduplication processes in other languages will be brought to bear on this debate.

\section{ACKNOWLEDGEMENTS}

This is a slightly revised version of an article in Hungarian ("Két reduplikációs folyamat a szaraiki nyelvben”) that appeared in Általános Nyelvészeti Tanulmányok 31, 11-27. We thank the editors of that volume, one Acta Linguistica reviewer, and audiences at several presentations for their constructive comments on previous versions. All usual disclaimers apply.

\section{REFERENCES}

Akinlabi, Akinbiyi. 1985. Tonal underspecification and Yoruba tone. PhD dissertation, University of Ibadan. 
Alderete, John, Jill Beckman, Laura Benua, Amalia Gnanadesikan, John J. McCarthy and Suzanne Urbanczyk. 1999. Reduplication with fixed segmentism. Linguistic Inquiry 30(3). 327-64.

Atta, Firdos. 2019. Phonetics and phonology of the Saraiki language: A first phonetic exploration and analysis in Optimality Theory. Ph.D. dissertation. Shanghai International Studies University.

Atta, Firdos, van de Weijer Jeroen and Lei Zhu. 2020. Illustrations of the IPA: Saraiki. Journal of the International Phonetic Association.

Booij, Geert E. 2010. Construction Morphology. Oxford: Oxford University Press.

Cohn, Abigail C. 1989. Stress in Indonesian and bracketing paradoxes. Natural Language \& Linguistic Theory $7.2,167-216$.

Frampton, John. 2009. Distributed reduplication (Linguistic Inquiry Monograph 52). Cambridge, MA: MIT Press.

Gordon, Raymond G. 2005. Ethnologue: Languages of the world. Dallas, TX: SIL International.

Hurch, Bernhard (ed.) 2005. Studies on reduplication (Empirical Approaches to Language Typology 28). Berlin and New York: Mouton de Gruyter.

Inkelas, Sharon and Cheryl Zoll. 2005. Reduplication: Doubling in morphology (Cambridge Studies in Linguistics 106). Cambridge and New York: Cambridge University Press.

Inkelas, Sharon and Cheryl Zoll. 2007. Is grammar dependence real? A comparison between cophonological and indexed constraint approaches to morphologically conditioned phonology. Linguistics 45 , 133-72.

Kager, René. 1999. Optimality Theory (Cambridge Textbooks in Linguistics). Cambridge: Cambridge University Press.

Lieber, Rochelle. 1982. Allomorphy. Linguistic Analysis 10, 27-52.

Lincoln, Peter. 1976. Describing Banoni, an Austronesian language of Bougainville. PhD dissertation, University of Hawaii.

Lynch, John and Malcolm Ross. 2002. Banoni. In John Lynch, Malcolm Ross and Terry Crowley (eds.) The oceanic languages. Richmond: Curzon Press. 440-55.

Marantz, Alec. 1982. Re reduplication. Linguistic Inquiry 13(3). 435-82.

McCarthy, John J. 1986. OCP effects: Gemination and antigemination. Linguistic Inquiry 17(2). 207-63.

McCarthy, John J. and Alan Prince. 1995. Faithfulness and reduplicative identity. In Jill N. Beckman, Laura Walsh-Dickey and Suzanne Urbanczyk (eds.), University of Massachusetts occasional papers in Linguistics 18: Papers in optimality theory. 249-384.

Moravcsik, Edith A. 1978. Reduplicative constructions. In Joseph H. Greenberg (ed.), Universals of human language, vol. 3. Stanford: Stanford University Press. 297-334.

Nadarajan, Shanthi. 2006. A crosslinguistic study of reduplication. Arizona Working Papers in Second Language Acquisition \& Teaching 13, 39-54.

Nevins, Andrew. 2005. Overwriting does not optimize in nonconcatenative morphology. Linguistic Inquiry 36(2). 275-87.

Nevins, Andrew. 2011. Phonologically conditioned allomorph selection. In Marc van Oostendorp, Colin J. Ewen, Elizabeth Hume \& Keren Rice (eds.), The blackwell companion to phonology, vol. 4. London: Wiley-Blackwell.

Nevins, Andrew \& Bert Vaux. 2003. Metalinguistic, shmetalinguistic: The phonology of shm-reduplication. Proceedings from the Annual Meeting of the Chicago Linguistic Society 39. 702-21. Chicago: Chicago Linguistic Society.

Pater, Joe. 2000. Non-uniformity in English secondary stress: The role of ranked and lexically specific constraints. Phonology 17(2). 237-74. 
Pater, Joe. 2009. Morpheme-specific phonology: Constraint indexation and inconsistency resolution. In Steve G. Parker (ed.) Phonological argumentation: Essays on evidence and motivation. London: Equinox. 123-54.

Prince, Alan S. \& Paul Smolensky. 2004 [1993]. Optimality Theory: Constraint interaction in generative grammar. London: Blackwell.

Rubach, Jerzy \& Geert E. Booij. 2001. Allomorphy in optimality theory: Polish iotation. Language 77(1). 26-60.

Russell, Kevin. 1997. Optimality theory and morphology. In Diana Archangeli \& D. Terence Langendoen (eds.), Optimality theory: An overview (Explaining Linguistics 1). Malden, MA: Blackwell. 102-33.

Shackle, Christopher. 1976. The Siraiki language of central Pakistan: A reference grammar. London: School of Oriental and African Studies (SOAS).

Singh, Amar Bahadur. 1969. On echo words in Hindi. Indian Linguistics 30(2). 185-93.

Siptár, Péter. 2009. Morphology or phonology? The case of Hungarian -ni. In Marcel den Dikken \& Robert M. Vago (eds.) Approaches to Hungarian 11: Papers from the 2007 New York Conference. Amsterdam and Philadelphia: John Benjamins. 197-215.

Soohani, Bahareh. 2017. The phonology of Iranian-Balochi dialects: Description and analysis. PhD dissertation, Leiden University.

Urbanczyk, Suzanne. 1999. Double reduplications in parallel. In René Kager, Harry van der Hulst \& Wim Zonneveld (eds.) The prosody-morphology interface. Cambridge and New York: Cambridge University Press. 390-428.

Urbanczyk, Suzanne. 2007. Reduplication. In Paul de Lacy (ed.) The Cambridge handbook of phonology. Cambridge: Cambridge University Press. 473-94.

Wilbur, Ronnie B. 1973. The phonology of reduplication. Bloomington, IN: Indiana University Linguistics Club.

Yip, Moira. 1998. Identity avoidance in phonology and morphology. Ms, University of California, Irvine. Rutgers Optimalty Archive (ROA-82). 